\title{
Determination of Design Seismic Motion by Considering Inland and Interplate Earthquakes
}

\author{
Haibo WANG
}

Senior Engineer, Foundation Engineering G., Structure Technology Development Div.

\begin{abstract}
Akihiko NISHIMURA
Manager, Foundation Engineering G., Structure Technology Development Div.

To determine the seismic ground motion for aseismic design after the Hyogoken-Nanbu Earthquake, it is required to take into consideration the earthquakes which occur either at the boundary of intercontinent plate or at the inland faults, although the return period of the latter for every inland fault may be longer than a thousand years. The seismic motion on bedrock with a shear wave speed over $400 \mathrm{~m} / \mathrm{s}$ is determined according to statistical analyses of strong seismic records observed in major earthquakes which occurred both in Japan and in the United States during recent years. In order to reduce deviation of recorded ground motion in statistics, influences of surface soil and topography have been avoided according to the information of the site of observation, and all records have been adjusted with respect to either the Closest Distance to Fault or the Equivalent Hypocentral Distance by attenuation function. Regarding the site where the seismic source can not be located, seismic risk factor is employed to determine the seismic ground motion. The factor is determined by seismic risk analysis based on the data of historical earthquakes as well as inland active faults.
\end{abstract}

Keywords : Design seismic motion, inland active fault, interplate earthquake, seismic risk factor

\section{Introduction}

The design seismic motion is very important in aseismic design of structures, because potential earthquakes are events associated with a great amount of uncertainty. It is desirable to determine the design seismic motion for a specific site according to risk factors such as the return period of earthquakes from certain seismic faults. However, the return period of earthquakes related to an inland active fault is not accurate enough at present, when compared with the service life of structure. Therefore, an extreme event associated with an inland active fault should be taken into account, unless it is evident that the fault will not move during the life of structure.

To determine the design seismic motion of a site, the geological and seismological information on inland active fault, historical activity of earthquakes around the site and interplate earthquakes near land must be analyzed carefully $^{2)}$. A general flowchart is given in Fig.1.

There are a number of ways to define the design seismic motion. The design seismic motion is defined below by the response spectra of acceleration on a free surface of bedrock, the shear wave speed of which is over $400 \mathrm{~m} / \mathrm{s}$. The choice of bedrock is to avoid the influences from local effects of specific site on the ground motion, such as the amplification due to the soft surface soil and irregular topography of ground. The influence due to geological conditions is very remarkable, as recognized in seismic records, and can be evaluated by calculating the responses of surface soil using a proper numerical model of surface ground with the design seismic motion as the incident motion. The corresponding artificial seismic

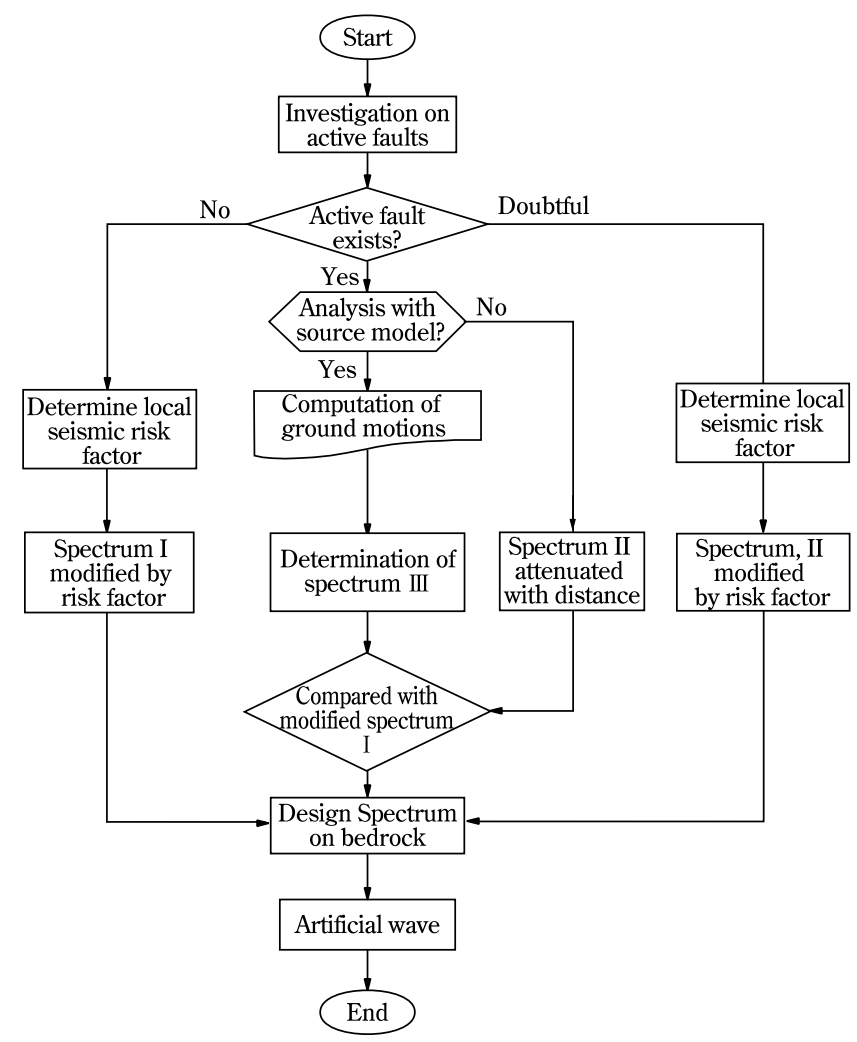

Fig. 1 General flowchart to determine the design seismic motion

wave can be generated by adjusting Fourier amplitudes of the wave according to the expected response spectra 
Table 1 Near-source seismic records from recent earthquakes

\begin{tabular}{|c|c|c|c|c|c|c|c|c|c|c|}
\hline \multirow[t]{2}{*}{ No } & \multirow[t]{2}{*}{ Earthquake } & \multirow[t]{2}{*}{ Name of seismic record } & \multicolumn{2}{|c|}{$\begin{array}{c}\text { Max. Acc. } \\
\text { (gal) }\end{array}$} & \multirow[t]{2}{*}{ Latitude } & \multirow[t]{2}{*}{ Longitude } & \multirow{2}{*}{$\begin{array}{c}\text { Equivalent } \\
\text { hypocentral } \\
\text { distance }\end{array}$} & \multirow{2}{*}{$\begin{array}{l}\text { Closest } \\
\text { Distance } \\
\text { to Fault }\end{array}$} & \multirow{2}{*}{\begin{tabular}{|c|} 
Ground \\
level of \\
observation
\end{tabular}} & \multirow{2}{*}{$\begin{array}{l}\text { Soil condition } \\
\text { at the position } \\
\text { of seismometer }\end{array}$} \\
\hline & & & NS & EW & & & & & & \\
\hline 1 & \multirow{7}{*}{$\begin{array}{c}\text { Hyogoken- } \\
\text { Nanbu }\end{array}$} & Port Island & 679.8 & 302.6 & 34.670 & 135.208 & 11.64 & 3.24 & GL-83 & $\mathrm{Vs}=450(\mathrm{~m} / \mathrm{s})$ \\
\hline 3 & & SGK, Kansai Elec. Power Co. & 293.9 & 319.8 & 34.743 & 135.442 & 34.57 & 24.65 & GL-97.0 & $\mathrm{Vs}=455(\mathrm{~m} / \mathrm{s})$ \\
\hline 4 & & Roko (Kobe University) & 272.0 & 306.5 & 34.725 & 135.240 & 14.99 & 6.90 & GL-9.5 & $0.5 \mathrm{~m}(240 \mathrm{~m} / \mathrm{s})$ layer over $\mathrm{Vs}=590(\mathrm{~m} / \mathrm{s})$ \\
\hline 5 & & Inagawa & 185.3 & 200.4 & 34.836 & 135.427 & 38.03 & 25.03 & GL-30 & $\mathrm{Vs}=780 \mathrm{~m} / \mathrm{s}$ \\
\hline 6 & & Great Bridge of East Kobe & 445.9 & 425.3 & 34.707 & 135.296 & 20.00 & 12.38 & GL-33 & Layer of $\mathrm{N}=18$ above GL-45 \\
\hline 7 & & Takaratuka & 683.6 & 600.9 & 34.809 & 135.344 & 29.93 & 16.88 & GL0.0 & $\mathrm{N}$ over $63,1.5 \mathrm{~m}$ surface layer with $\mathrm{N}=5$ \\
\hline 8 & & New Kobe substation & 510.7 & 584.2 & 34.731 & 135.250 & 16.52 & 7.53 & GL0.0 & $\mathrm{Vs}=300 \mathrm{~m} / \mathrm{s}, 4 \mathrm{~m}$ surface layer $\mathrm{Vs}=200 \mathrm{~m} / \mathrm{s}$ \\
\hline 9 & Coyote Lake & San Ysidro & 314.6 & 408.8 & 37.026 & 121.484 & & 1.0 & GL0.0 & Rock \\
\hline 10 & \multirow{2}{*}{ Loma Prieta } & Santa Cruz UCSC & 433.1 & 401.5 & 37.00 & 122.06 & 18.01 & 12.19 & GL0.0 & Limestone \\
\hline 11 & & Gilroy\#1-Gavilan Coll. & 426.6 & 433.6 & 36.973 & 121.572 & 26.56 & 12.21 & GL0.0 & Franciscan Sandstone \\
\hline 12 & Landers & Joshua Tree fire station & 268.3 & 278.4 & 34.131 & 116.314 & 16.90 & 10.79 & GL0.0 & Shallow alluvium over granite bedrock \\
\hline 13 & \multirow{2}{*}{ Northridge } & Tarzana Cedar Hill Nursery & 970.7 & 1744.5 & 34.160 & 118.534 & 20.63 & 17.87 & GL0.0 & Thin alluvium over siltstone \\
\hline 14 & & Pacoima Kagel Canyon & 424.2 & 295.2 & 34.288 & 118.375 & 18.73 & 8.98 & GL0.0 & Rock \\
\hline
\end{tabular}

of acceleration, with their phases reflecting the non-stationary property of seismic motion.

There are three kinds of spectra defined in the flowchart (Fig.1). Spectrum I represents mainly the seismic motion caused by near land interplate earthquakes of magnitude 8 . In addition, the inland active fault, which will cause an earthquake of magnitude less than 6.5 , is difficult to be found since its size is not big enough to reach the ground surface. According to the historical earthquakes, this type of earthquake may happen in most areas of Japan. Consequently, the seismic motion due to this type of earthquake is also covered by Spectrum I therefore this spectrum is regarded as the minimum seismic motion to be verified in aseismic design.

Spectrum II represents the seismic motion caused by the earthquake of inland active fault at a site straight above the fault, which is determined by statistical analyses of seismic records observed in near-source area in recent earthquakes. Spectrum III also represents the seismic motion from the earthquakes of inland active faults, but is determined from the seismic source model of a fault by analysis, if such a model is available.

Which spectrum should be used as the design seismic motion depends on the results of investigation of inland active faults. There are three possible results from the investigation. First, if there is no active fault near the site, the seismic motion of Spectrum $I$ is to be used as design seismic motion after modified by the risk factor of the area. Second, there are cases where one or more active faults exist near the site. When the parameters of seismic source for the fault can be properly decided, the design seismic motion will be figured out from analysis. Otherwise, the seismic motion of Spectrum II attenuated according to the distance between the fault and site, will be used as the design seismic motion. Because the motion decreases with the distance from the fault, whichever the larger motion is to be used as the design seismic motion, after the motions decided above are compared with Spectrum I modified by the risk factor of the area. Thirdly, there are sites where the existence of active fault is very doubtful and difficult to confirm due to very deep sedimentary deposit, or there exists a complex tectonic structure beneath the site, such as the Kanto area where three plates encounter with each other. Hence, the de- sign seismic motion is Spectrum II modified by the risk factor of the area.

\section{Near-source seismic motion of inland fault}

There are still many problems to be solved when using a seismic source model of fault to predict the seismic ground motion at a site for the purpose of aseismic design, such as the distribution of the asperity on the fault plane, the start point of rupture, etc. To consider these uncertainties of it, it is very useful to evaluate the seismic motion near inland fault from statistical analyses of near-source strong seismic records observed in recent years. Below summarized is a method to determine Spectrum II based on strong seismic records.

\section{1 Seismic records}

Table 1 shows the list of records observed in recent earthquakes in the United States and Japan, HyogokenNanbu (1995, M7.2), Coyote Lake (1979, M5.9), Loma Prieta (1989, M7.1), Landers (1992, M7.5) and Northridge (1994, M6.7). The records are chosen to satisfy the following requirements.

(1) The soil condition at the station of seismometer meets the condition of the aforementioned bedrock.

(2) The maximum acceleration is greater than $100 \mathrm{gal}$.

(3) The Closest Distance to Fault is less than $30 \mathrm{~km}$.

The list shows that the records of Hyogoken-Nanbu Earthquake are all in the ground. Theoretically, deconvolution shall be carried out to separate the incident wave from the record. The original records are used here instead, because it is difficult to get a result that is reasonably closer to incident wave than original record, as there are a number of unsolved problems in the deconvolution analysis for strong ground motion. Besides, the influence of the surface soil would not be too strong since the shear wave speed of soil at all sites is higher than $450 \mathrm{~m} / \mathrm{s}$ anywhere, except at the Great Bridge of East Kobe.

The acceleration response spectra of the selected records are illustrated in Fig.2. It can be found that the response accelerations vary from 200 (gal) to 3000 (gal) 


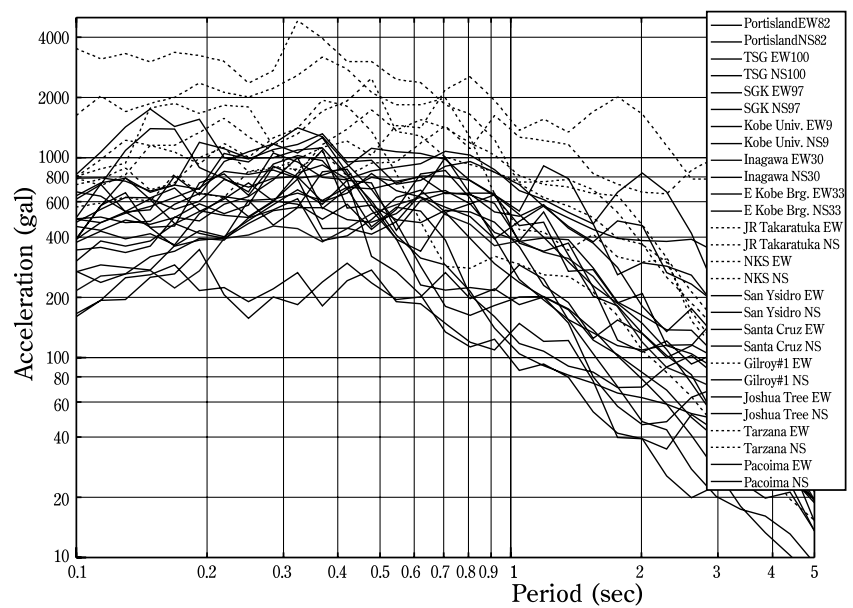

Fig. 2 Acceleration response spectra of observed records at near-source area of inland earthquakes

in the range of short period and from tens of gals to 1000 (gal) in the range of long period. As the soil conditions at the observation stations have been carefully chosen, this wide variation may be attributed to the following.

(1) Difference in the mechanism of seismic sources

(2) Difference in the propagation of seismic waves

(3) Influence of irregular topography

The influence of irregular topography can be avoided only by selecting records according to the geological condition if available. Through a careful investigation, it is found that the records at Tarzana, Northridge earthquake (1994, M6.7), New Kobe substation and Takaratuka, Hyogoken-Nanbu earthquake (1995, M7.2), are influenced strongly by special topography ${ }^{1)}$,14), so that these records are excluded from statistical analyses.

As to the influence of the propagation of seismic waves, the profiles in deep ground in the range of several kilometers as well as the $\mathrm{Q}$ factor (quality factor) are considered to be very important, but they are out of the scope of this study. However, a number of attenuation functions of ground motion have been proposed, in which influences on propagation are all considered in an average sense. By using the existing attenuation function, we compensate the recorded seismic motions to a same distance from the seismic source so that the variation of ground motion due to propagation can be minimized. The rest variation of ground motion in statistics is attributed to the properties of the seismic source or other unclear reasons.

\section{2 Compensation by attenuation function}

Among the attenuation functions proposed, the measurement of the distance between the site and the seismic source is very important to decide the near-source strong ground motion, where the extent of fault plane must be considered properly. To satisfy the above requirement, the Closest Distance to Fault (CDF) has been widely used recently. The following is an attenuation function of response spectra of ground motion based on CDF which is proposed by Fukushima ${ }^{3)}$.

$$
\begin{aligned}
\log S(T) & =a_{1}(T) M_{w}^{2}-a_{2}(T) M_{w}+b(T) \cdot R \\
& -\log \left(R+0.025 \times 10^{0.42 M_{w}}\right)+\sum c_{j}(T) I_{j}
\end{aligned}
$$

in which $M_{w}, R$ and $T$ are the moment magnitude, the Closest Distance to Fault and the period, respectively; $a_{1}, a_{2}$ and $b$ are coefficients of regression; $c_{j}$ is the coefficients related to site properties.

On the other hand, Ohno et al. ${ }^{4)}$ proposed another type of attenuation relation based on Equivalent Hypocentral Distance, this is determined by the energy radiated from the finite fault plane.

$$
\begin{aligned}
& \log S(T)=a(T) M_{w}-\log X_{e q}-b(T) X_{e q}+c(T)+\Delta s(T) \\
& X_{e q}^{-2}=\sum_{i=1}^{N} d_{i}^{2} X_{i}^{-2} / \sum_{i=1}^{N} d_{i}^{2}
\end{aligned}
$$

where $X_{e q}$ denotes the Equivalent Hypocentral Distance; $N, X_{i}$, and $d_{i}$ are the number of small areas used in calculation, the distance between the site and the center of the area $i$, and the seismic moment on the area $i$, respectively.

The Closest Distance to Fault and Equivalent Hypocentral Distance given in Table 1 for every site of record are calculated according to the fault models published by USGS for earthquakes in USA and by Irekura for Hyogoken-Nanbu Earthquake, respectively.

There is an important phenomenon for the ground motion in near-source area, in that it tends to saturate as the site is getting close to fault presumably for the following reasons. Firstly, most of active fault planes are nearly vertical to the ground surface. Secondly, the thickness of the crust of the earth is from 15 to $20 \mathrm{~km}$. In consequence, the size of the fault in the horizontal direction will increase as the scale of the earthquake gets larger, so that the affected area becomes larger too. However, the strength of ground motion at the near-source area will not increase because the energy does not concentrate but widely spreads on the whole plane of the fault. Since we need to infer the ground motion right above the fault, we can omit the influence of the magnitude while taking into account only the distance between the site and the fault, compensating for the observed records by the aforementioned attenuation relation.

After all fault models are examined, the Equivalent Hypocentral Distance of destination is taken as $12 \mathrm{~km}$ in this study. The compensated response spectra of acceleration are shown in Fig. 3.

Because, overall, the compensation from the attenuation function gives a ground motion closer to the fault than original records, all spectra become larger. The upper limit is about 2000gal, except those of SGK EW97 and Gilroy\# 1 Gravilan Coll.EW records. As expected, the deviation of ground motion from the statistical mean value becomes smaller for all periods. When compared with those in the short period, the improvement in the long period is slight, to imply the existence of dominating effects from the seismic source and the structure in deep ground.

Fig. 4 compares the statistical results based on the 


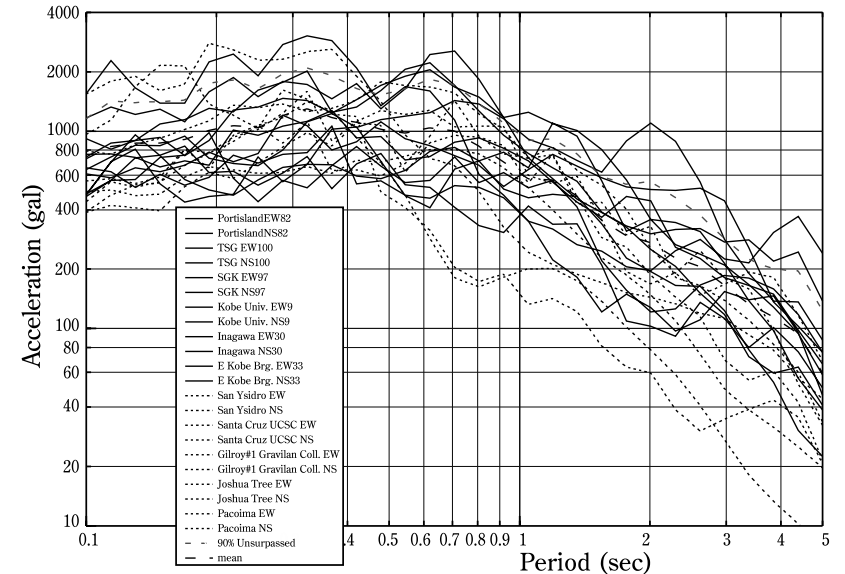

Fig. 3 Acceleration response spectra of observed records after compensated with attenuation relation using Equivalent Hypocentral Distance

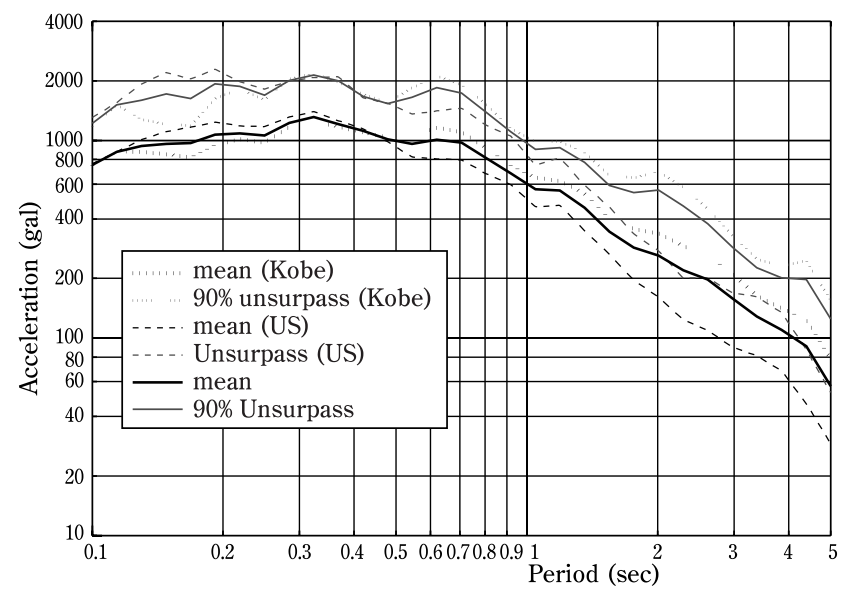

Fig. 4 Comparison of the statistical results based on the seismic records in USA and Kobe, respectively

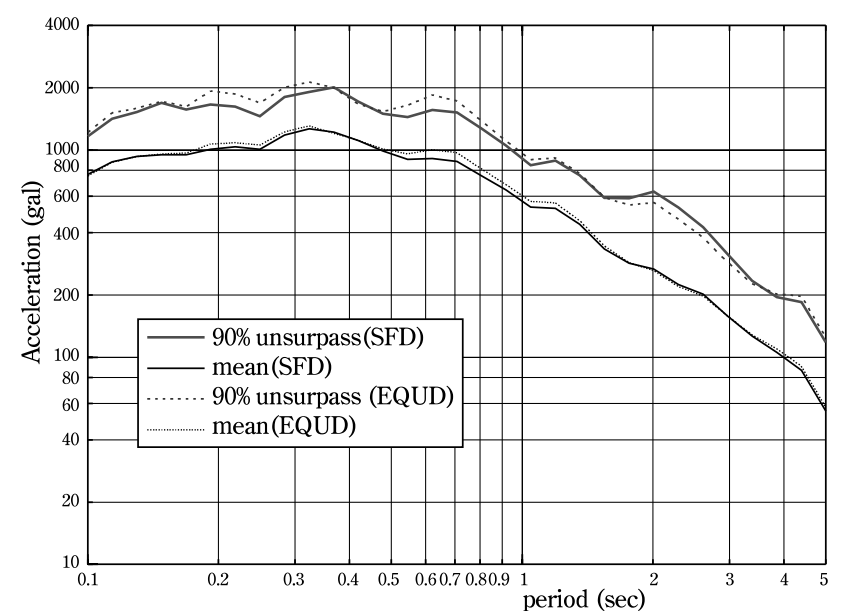

Fig. 5 Comparison of the statistical results using Closest Distance to Fault and equivalent hypocentral distance attenuation relations

seismic records of USA and Kobe. They satisfactorily agree with each other for the period up to 1.0 second. For the period longer than 1.0 second, the records at Kobe give larger response spectra. This difference would be a major cause of larger deviation of total statistical results in the long period range. Meanwhile, it can also be found that the statistical results become smoother as the number of records increases.

The attenuation function based on CDF is also used, where the distance of destination is taken as $2 \mathrm{~km}$. The point of $2 \mathrm{~km}$ from fault is the place right above it, because little portion of energy will be radiated from the range within $2 \mathrm{~km}$ from the ground surface, even though the fault reaches and appears on the ground surface. There is not much difference between the mean of response spectra and that based on the Equivalent Hypocentral Distance, but the values of $90 \%$ unsurpassed probability show a little difference (Fig. 5). This illustrates that the statistical result of ground motion right above the fault is almost independent of attenuation relation of the Closest Distance to Fault or the Equivalent Hypocentral Distance.

\section{3 Seismic motion straight above the inland fault}

In view of the limited number of records adopted at present as well as unknown properties of earthquakes in the future, it is wise and reasonable to determine the design seismic motion according to a certain unsurpassed value, rather than by taking the envelope of the maximum values.

To what degree the unsurpassed probability should be taken is very important but difficult to determine. It usually depends on a subjective judgement. For railway structures, the following considerations are necessary.

(1) Railways are a means of mass transportation directly related to the safety of passengers.

(2) A failure at one point of a railway system will affect the whole route, and it is very costly and impossible not to have a bypass for the same railway.

(3) The seismic records used are limited possibly with unknown factors.

In the light of above considerations, a high unsurpassed probability is strongly expected, but the value $90 \%$ is believed to be acceptable and adequate when the accuracy of the whole process of aseismic design is taken into consideration.

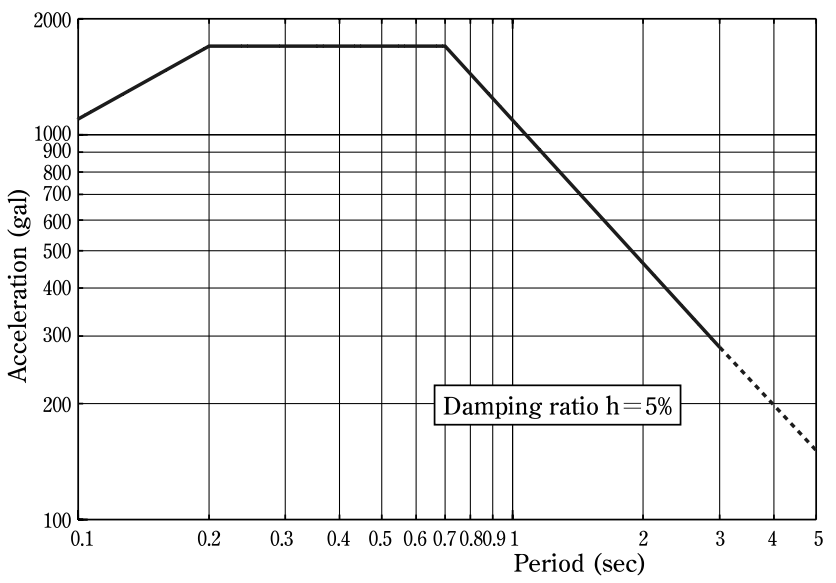

Fig. 6 Response spectra of acceleration for design seismic motion straight above an inland fault 
It is not difficult to get the value of a certain unsurpassed probability if we assume that the response spectra at the given period is normally distributed. The $90 \%$ unsurpassed value is given in thick dot line in Fig.3. Due to the influence of the records at SGK (Hyogoken-Nanbu earthquake) and Gilroy Gavilan Coll. (Loma Prieta earthquake), the apparent value near $0.3 \mathrm{~s}$ in period is over 2000 gal, which may be attributed to some local effects of two sites. Therefore, we use three straight lines on the log-log plot to define the response spectra of acceleration for the design seismic motion (Fig. 6) called Spectrum II. Its values are below.

(1) 1100 gal at $0.1 \mathrm{~s}$ in period

(2) $1700 \mathrm{gal}$ between $0.2 \mathrm{~s}$ and $0.7 \mathrm{~s}$ in period

(3) $154 \mathrm{gal}$ at $5.0 \mathrm{~s}$ in period.

This is the motion straight above a fault. Therefore, it can be reduced by the attenuation relation according to the distance between the seismic fault and the site. Here the Equivalent Hypocentral Distance is recommended.

\section{Seismic motion of interplate earthquake}

In the standards of seismic design used before the Hyogoken-Nanbu earthquake, the seismic motion of interplate earthquake was provided. The response spectra of acceleration for design were about $1000 \mathrm{gal}$ on a standard ground surface. In order to treat the earthquakes of inland fault and interplate on the same basis, the same statistical analysis and compensation carried out so far are applied to the seismic records of interplate earthquakes.

\section{1 Seismic records of interplate earthquake}

The recent interplate earthquakes occurred near Japan are shown in Fig. 7, from which over a hundred records with the maximum acceleration larger than $100 \mathrm{gal}$ have been collected. The distances between the site of seismometer and the source are mostly from 100 to $200 \mathrm{~km}$ (Fig. 8 ).

From these records, 27 have been chosen, according

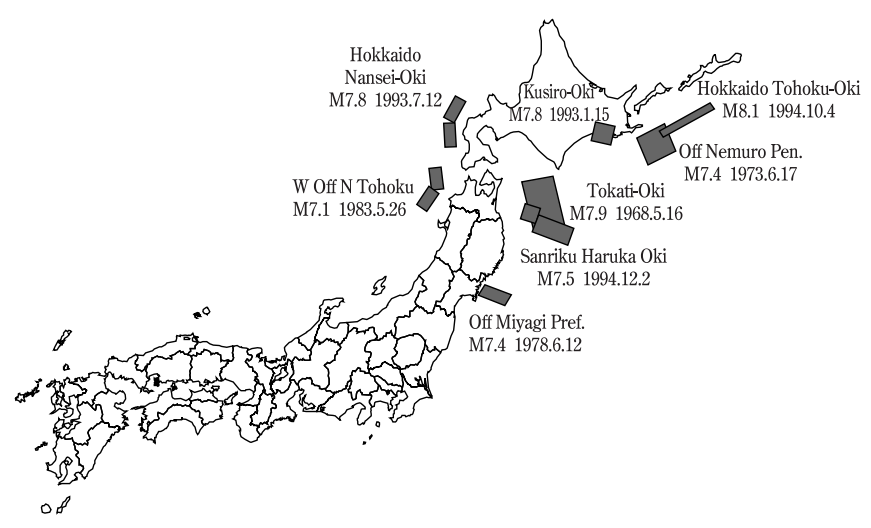

Fig. 7 Interplate earthquakes occurred in Japan recently

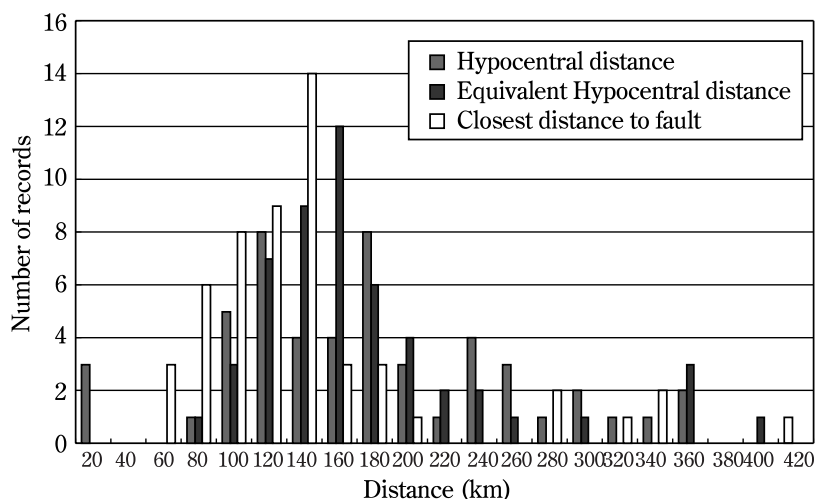

Fig. 8 Distribution of distance between seismometer and seismic source

to the following requirements, their detail information is given in Table 2 .

(1) Both Equivalent Hypocentral distance and Closest Faults Distance are within 200 kilometers.

(2) The soil condition of the observing station is good.

(3) No unnatural peaks exist on the Fourier spectra of the records.

The acceleration response spectra of those records are shown in Fig. 9.

Table 2 Seismic records from recent interplate earthquakes in Japan

\begin{tabular}{|c|c|c|c|c|c|c|c|c|c|}
\hline Earthquake & No & Recorded site & Latitude & Longitude & $\begin{array}{c}\text { Hypocentral } \\
\text { distance } \\
(\mathrm{km})\end{array}$ & $\begin{array}{c}\text { Equivalent } \\
\text { Hypocentral } \\
\text { distance } \\
(\mathrm{km})\end{array}$ & $\begin{array}{c}\text { Closest } \\
\text { Distance to } \\
\text { Fault } \\
(\mathrm{km})\end{array}$ & $\begin{array}{c}\text { Position of } \\
\text { seismometer }\end{array}$ & $\begin{array}{l}\text { Direction of } \\
\text { records }\end{array}$ \\
\hline Off Nemuro Pen. (June 17, 1973) & 2 & Otanoshike Brg. & 43.0083 & 144.271 & 136.9 & 163.7 & 109.7 & GL & $\overline{L G}$ \\
\hline \multirow{2}{*}{ Off Miyagi Pref. (June 12, 1978) } & 3 & Kaihoku Brg. & 38.445 & 141.313 & 81.6 & 70.2 & 56.5 & GL & LG, TR \\
\hline & 4 & Ofunato-Bochi & 39.00 & 141.733 & 101.7 & 86.8 & 71.6 & GL & N41W, E41N \\
\hline \multirow{6}{*}{ Kusiro-Oki (Jan. 15, 1993) } & 6 & Urakawa & 42.158 & 142.781 & 151.6 & 174.4 & 149.1 & GL & NS, EW \\
\hline & 7 & Hanasaki Port & 43.2800 & 145.589 & 109.4 & 156.4 & 131.3 & GL & N20E, E20S \\
\hline & 8 & Tokachi Port & 42.2889 & 143.324 & 106.5 & 141.7 & 121.8 & GL & NS, EW \\
\hline & 9 & Hiroo Brg. & 42.2792 & 143.319 & 107.5 & 142.4 & 122.4 & GL & LG, TR \\
\hline & 10 & Otanoshike Brg. & 43.0083 & 144.271 & 19.8 & 105.2 & 100.1 & GL & $\mathrm{LG}, \mathrm{TR}$ \\
\hline & 11 & Chiyoda Brg. & 42.9197 & 143.389 & 81.5 & 123.3 & 108.2 & GL & LG, TR \\
\hline \multirow{2}{*}{ Hokkaido Nansei-Oki (July 12, 1993) } & 12 & Muroran Port & 42.3167 & 140.967 & 153.3 & 149.0 & 129.3 & GL & NS, EW \\
\hline & 13 & Kamitorizawi Brg. & 42.1014 & 140.563 & 124.6 & 120.1 & 91.4 & GL & $\mathrm{LG}, \mathrm{TR}$ \\
\hline
\end{tabular}




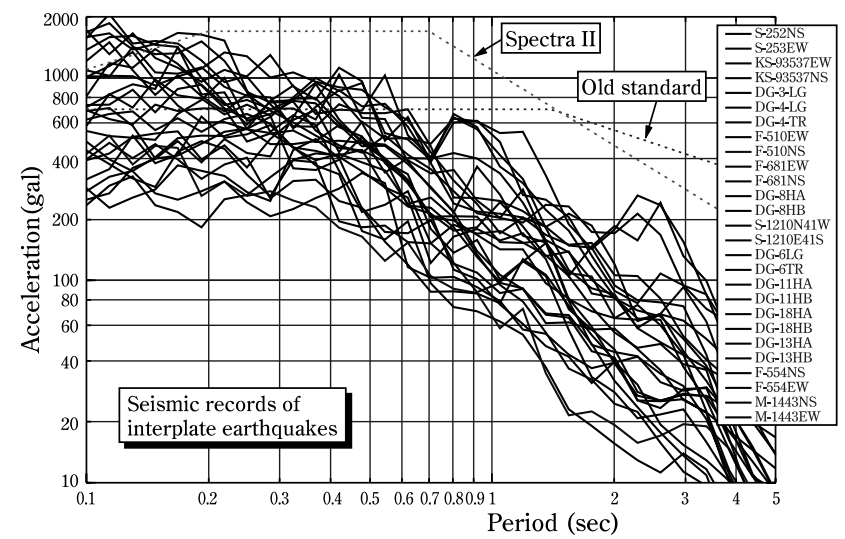

Fig. 9 Acceleration response spectra of observed records of interplate earthquake near Japan

Shortest fault distance $(\mathrm{km})$

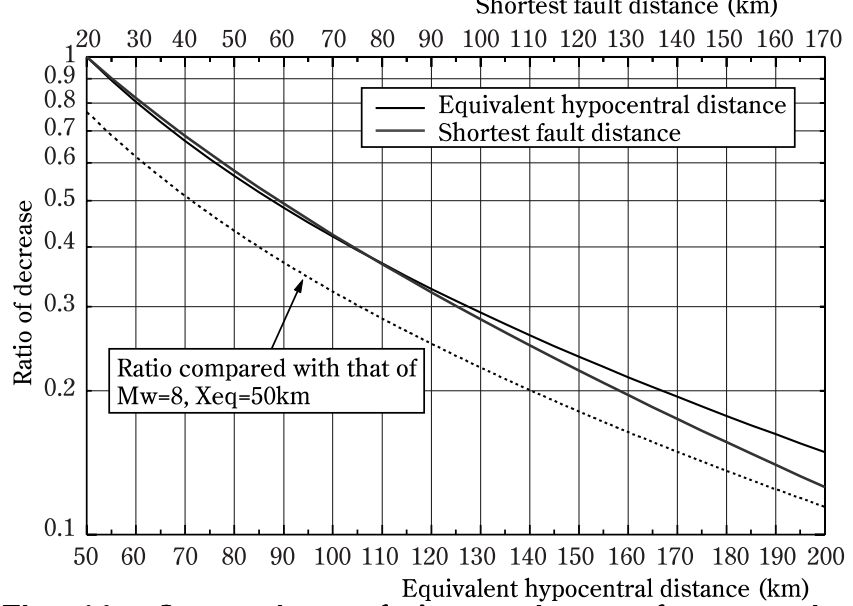

Fig. 10 Comparison of the tendency of attenuation between two attenuation functions (Period of 1 second)

\section{2 Compensation by attenuation function}

The attenuation relations used for inland earthquakes are also used here. As we have to take the scale of earthquake into consideration because the seismic motion to be inferred is at the site a little far from of the seismic source, the motion becomes very sensitive to the scale of earthquake.

Since the physical meanings of Equivalent Hypocentral Distance and Closest Distance to Fault are different, the tendency of attenuation implied in each attenuation function differs from each other. Fig. 10 compares the calculations by the two formulae, in which the scale of the earthquake is taken as $M_{w}=7.8$, and the standard Closest Distance to Fault and Equivalent Hypocentral Distance are taken as $20 \mathrm{~km}$ and $50 \mathrm{~km}$, respectively, according to the mean values of the records. It is evident that the attenuation is almost the same for two formulae. However, if the motion of $M_{w}=8.0$ is taken as the standard, the attenuation by Equivalent Hypocentral Distance is about 0.767 times (dash line in Fig. 10), although no significant changes appear when the attenuation function uses CDF.

This difference is attributed to the definition of two distances. Let's assume empirical relationships ${ }^{9}$ between the extension of fault $L$ and the seismic moment $M_{0}$ as well as that between the moment $M_{0}$ and moment magnitude $M_{w}$.

$\log M_{0}=0.2619 \log L+22.445$

$$
M_{w}=\left(\log M_{0}-16.1\right) / 1.5
$$

From the above, we obtain the relationship between the extension of a fault and the magnitude of earthquake generated from it,

$$
\log L=\left(M_{w}-4.23\right) / 1746
$$

The length of the fault when $M_{w}$ is 8.0 and 7.8 will be $144 \mathrm{~km}$ and $110 \mathrm{~km}$, respectively. Furthermore, taking the width of the fault as a half of its length and the seismic moment as uniformly distributed on its plane, we can figure out that the minimum Equivalent Hypocentral Distance is $34.9 \mathrm{~km}$ and $27.2 \mathrm{~km}$, respectively. This means that the Equivalent Hypocentral Distance becomes bigger as the scale of the earthquake increases, even though the distance between the observer and one edge of the fault is kept unchanged. To have the same ground motion as that at the Equivalent Hypocentral Distance of $50 \mathrm{~km}$ and $M_{w}=7.8$, the distance should be $62.5 \mathrm{~km}$ when $M_{w}=8.0$.

On the other hand, the motion will be affected dominantly by the seismic energy closest to the observer, so that the part of fault over $100 \mathrm{~km}$ away has little influence. If the CDF is used, the seismic motion for the same $\mathrm{CDF}$ is almost independent of the scale of earthquake

\section{Table 3 Objective distance and scale of earthquake used

\begin{tabular}{|c|c|c|c|c|}
\hline & \multicolumn{2}{|c|}{ Closest Distance to Fault } & \multicolumn{2}{|c|}{ Equivalent hypocentral distance } \\
\hline & $\begin{array}{c}\text { Objective } \\
\text { distance } \\
(\mathrm{km})\end{array}$ & $\begin{array}{c}\text { Scale of } \\
\text { Earthquake } \\
\left(M_{w}\right)\end{array}$ & $\begin{array}{c}\text { Objective } \\
\text { distance } \\
(\mathrm{km})\end{array}$ & $\begin{array}{c}\text { Scale of } \\
\text { Earthquake } \\
\left(M_{w}\right)\end{array}$ \\
\hline Case 1 & 30 & - & 50 & - \\
\hline Case 2 & 50 & - & 80 & - \\
\hline Case 3 & 80 & - & 100 & - \\
\hline Case 4 & 30 & 8.0 & 50 & 8.0 \\
\hline Case 5 & 50 & 8.0 & 80 & 8.0 \\
\hline Case 6 & 80 & 8.0 & 100 & 8.0 \\
\hline
\end{tabular} for compensation}

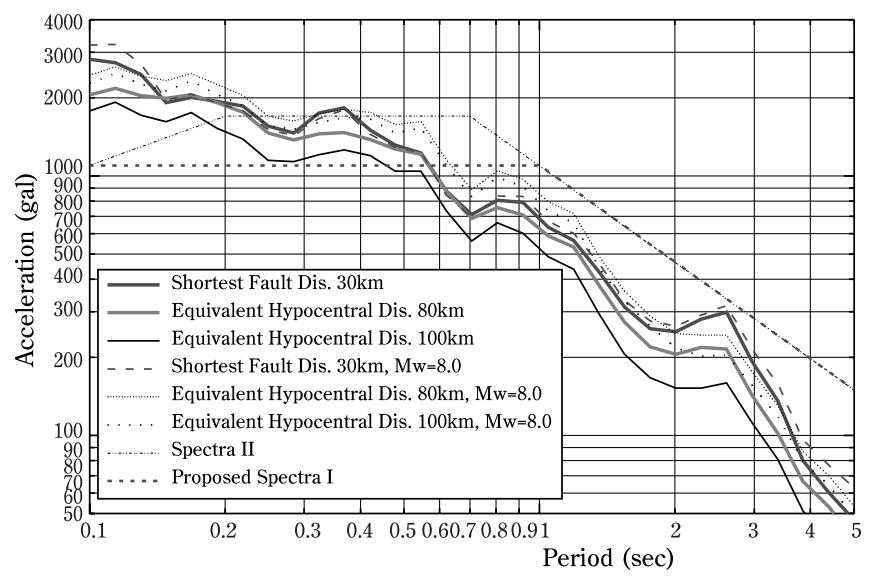

Fig. 11 Comparison of statistical results after compensation Acceleration response spectra 
provided that the scale is large enough.

In consideration of the above difference between the attenuation function based on Equivalent Hypocentral Distance and Closest Distance to Fault, several objective distances and scales of earthquake have been set, as shown in Table 3. Besides, if the actual amplitude is larger than 8.0, no corrections are carried out on the scale. Since the plate generally moves downward when approaching the land, it is reasonable to take the position above the deepest edge of the fault in the calculation of the minimum distance. The objective distance used for compensation should be no smaller than this minimum distance of the fault. For example, the minimum CDF for the Kusiro earthquake is $103 \mathrm{~km}$, because it is a very deep earthquake.

After compensation, the seismic motions become larger, but the deviation shows little change. One major reason is the accuracy of the model for seismic sources, but it is out of the scope of this paper. Here uniform distributed seismic moment has been assumed simply.

A comparison between the statistical results (values of $90 \%$ unsurpassed probability) of compensated records is shown in Fig. 11. It is easy to confirm that the influence of the scale of earthquake is insignificant if Closest Distance to Fault is adopted, and the motion is very sensitive to the scale on the other hand when Equivalent Hypocentral Distance is used, consistent with the previous discussion.

In Fig. 11 we find that the response spectra for Equivalent Hypocentral Distance being $80 \mathrm{~km}$ and the scale $M_{w}=8.0$, are larger than those for Closest Distance to Fault of $30 \mathrm{~km}$ and the same scale earthquake. The distance of $30 \mathrm{~km}$ in CDF implies the position directly above the edge of a fault if the average depth of the fault is considered for interplate earthquakes.

Spectrum II is also plotted in Fig.11. The compensated level for interplate earthquake is smaller than Spectrum II in the range of long period, but larger in the range of very short period. This may reflect the characteristics of the interplate earthquake or some influence due to irregular topography, which needs further investigation from the observation stations.

It is desirable to define the spectra based on the statistical results at a given unsurpassed probability, but the results here are not accurate enough. Meanwhile, the design spectra used in the old standard have to be taken into account as well. In consequence, the design seismic motion, or Spectrum I, is determined on the base of statistical results for Equivalent Hypocentral Distance of $80 \mathrm{~km}$ and the scale of $M_{w}=8.0$. As shown in Fig. 11 with a dash line, the Spectrum I is defined by two straight lines in log-log plot as follows.

(1) 1100 gal between $0.1 \mathrm{~s}$ and $1.0 \mathrm{~s}$ in period

(2) $154 \mathrm{gal}$ at $5.0 \mathrm{~s}$ in period

For the purpose of simplicity in design, the response spectra are defined as the same as for the period longer than 1.0 second. As to the level, the design spectra are larger than the statistical ones for the period longer than 0.65 seconds, but smaller for the shorter period. When compared with the original records in Fig. 9, the design spectra are larger in the period longer than 0.2 seconds. In General, the vibration of high frequency decreases much quicker due to the damping in structure and soil and the displacement associated with it is small too. Whence, the design spectra defined here does not underestimate the actual ground motion for the aseismic design.

Besides, the level of Spectrum I, even when multiplied by the smallest risk factor which will be discussed later, can cover the ground motion due to an earthquake with the magnitude less than 6.5 which may occur inland without making its fault reach the ground surface. This can be easily verified through the attenuation function given above, where the depth of a fault center is assumed as $10 \mathrm{~km}$ from the ground surface.

\section{Seismic risk factor around Japan}

For the region where the seismic source is not clear, seismic risk factor is necessary to define the design seismic motion. The seismic risk factor is usually decided from historical earthquakes. However reliable data of historical earthquakes has been available for only about a hundred years in Japan. It is obviously insufficient to evaluate the seismic motion due to inland faults with a return period longer than a thousand years. In order to make up for this insufficiency, the data of known active faults are also employed to make a reliable estimation of risk factor all over Japan. The risk factor referred to here gives only a relative potential of strong seismic motion all over Japan.

\section{1 Method of analysis}

Based on the data of historical earthquakes as well as the data of active faults, seismic risk analyses are carried out, accordingly, to evaluate the risk factor ${ }^{12), 13)}$. In the analyses, the attenuation relation based on Equivalent Hypocentral Distance has been used. For historical earthquakes without reliable source information, a lower limit has been introduced for Equivalent Hypocentral Distance.

For the data of historical earthquakes, it is assumed that only one event will occur during the period of data employed. For the data of active faults, the return period is reckoned from the length, quantity of dislocation, seismic moment as well as relative moving rate per year of the fault. The quantity of dislocation and seismic moment can be related by the following equation.

$$
M_{0}=\mu D S
$$

in which $\mu$ is the shear stiffness, $D$ the average quantity of dislocation and $S$ the area of the fault.

Because the data of historical earthquakes are not equally accumulated for all areas, the period during which data is used is set as

$$
\begin{array}{ll}
5.5 \leqq \mathrm{M}<6.0 & 1926 \sim 1996 \\
6.0 \leqq \mathrm{M} & 1885 \sim 1996
\end{array}
$$

The data from 1926 are quoted from the catalog of earthquake issued by the Agency of Meteorology, Japan, and the data before are based on the Utsu's catalog ${ }^{15)}$. Besides, very deep earthquakes, whose hypocenter are 
deeper than $100 \mathrm{~km}$ are deleted from the list, since only two cases of trifling damage related have been reported until now.

As to the data of active faults, only those with high reliability are employed, that is, those of reliability I and II recorded on Active Faults in Japan ${ }^{8)}$. The relative creep of fault is related to the level of activity, proposed by Kameda et al. ${ }^{11)}$

Activity Level A: $3.3 \mathrm{~m} / 1000$ years

Activity Level B: $0.32 \mathrm{~m} / 1000$ years

Activity Level C: $0.053 \mathrm{~m} / 1000$ years

\section{2 The results of Analyses}

Because the relative level of expected response acceleration is not very sensitive to the period, the values at 0.5 seconds are calculated for all Japan with a grid of $5 \mathrm{~km}$ both in length and in width. Fig. 12 shows the results of analyses combining those based on historical earthquakes and active faults, with a return period of 1000 years.

The risk factors are to be divided into three levels, $1.0,0.85$ and 0.70 , from the viewpoint of engineering, and

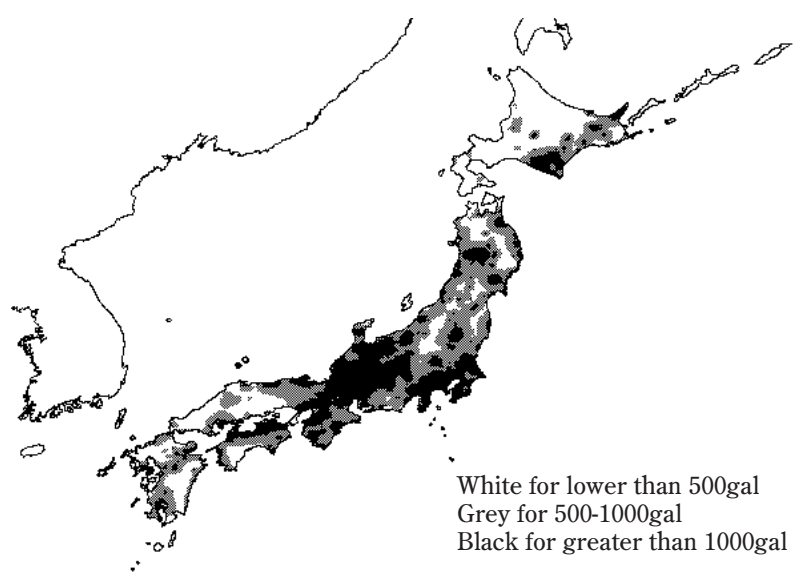

Fig. 12 Distribution of expected ground motion with a return period of a thousand years in Japan

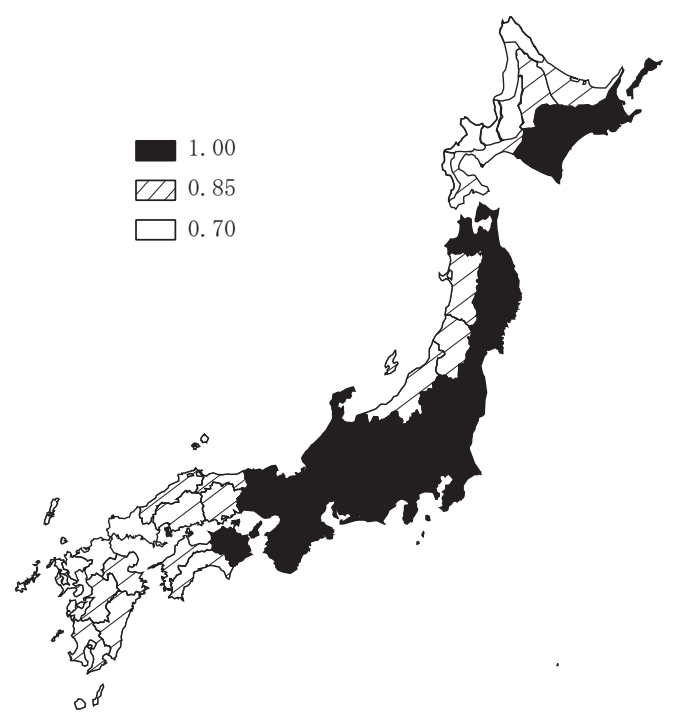

Fig. 13 Seismic risk factors in Japan the area is divided into prefectures or branches in Hokkaido (shown in Fig. 13). To determine the factor for each area, the results of seismic risk analysis with a return period of 50,100, 1000 years are considered together. In addition, there are the following essential factors to be considered.

(1) The level of response acceleration is divided into steps as,

less than $200 \mathrm{gal}$, from 200 to $400 \mathrm{gal}$, higher than $400 \mathrm{gal}$, for return period of 50 years,

less than $300 \mathrm{gal}$, from $300 \mathrm{gal}$ to $500 \mathrm{gal}$, higher than $500 \mathrm{gal}$, for return period of 100 years

less than 500 gal, from 500 gal to 1000 gal, higher than $1000 \mathrm{gal}$, for return period of 1000 years

(2) The largest factor among those of three return periods is adopted.

(3) The attenuation is smaller than the average in Japan for Northeast region neighboring with the $\mathrm{Pa}-$ cific, in historical earthquakes.

(4) The risk factor of an area is taken as 0.85 , if it is adjacent to an area with a risk factor 1.0 for the purpose of continuity.

(5) In consideration of the risk factor of an area in the previous standard, the new risk factor is not smaller than 0.85 if the old one was 1.0 , and not larger than 0.85 if the old one was 0.7 , except for the area where the risk factors are higher for all three return periods.

\section{Conclusions}

In this paper, the ground motions due to inland earthquakes and interplate earthquakes have been examined based on the strong seismic records. A procedure for the determination of design seismic motion was proposed, in which inland active faults, historical earthquakes, as well as interplate earthquakes near the land should be investigated carefully.

The design seismic motion for the inland fault, known as Spectrum II, is inferred according to the statistical results of strong seismic records observed in near-source areas, at an unsurpassed probability of $90 \%$. And compensation has been carried out by the attenuation functions for all records in order to get the ground motion straight above the fault. It is found that the results of compensation have no significant difference either by Equivalent Hypocentral Distance or by Closest Distance to Fault.

The design seismic motion due to interplate earthquakes, known as Spectrum I, is determined according to the statistical results of strong seismic records observed as well as based on some judgement in engineering. Meanwhile, the level of Spectrum I, even when multiplied by smallest risk factor, can cover the seismic motion due to an earthquake of inland with Mw less than 6.5 whose fault does not reach the ground surface. Therefore, Spectrum $\mathrm{I}$ is also worked as the minimum level of ground motion to be verified in aseismic design.

The risk factors, which reflect the relative level of expected ground motion all over Japan, are determined according to the results of seismic risk analyses based on 
the data of historical earthquakes and active faults, as well as some based on judgement in engineering. The factors will be applied where the seismic source is difficult to position.

\section{References}

1) "Report on the investigation of disaster of Earthquake in Hanshin-Awaji", Committee on the investigation of disaster of Earthquake in Hanshin-Awaji, The Japanese Geotechnical Society. (in Japanese)

2) "Proposal on Earthquake Resistance for Civil Engineering Structures", Special task committee of earthquake resistance of civil engineering structures, Japan

3) Yoshimitsu Fukushima : "Empirical prediction for strong ground motion reflected on theoretical backgrounds of source and propagation of seismic wave", ORI Report 93-07, Ohsaki Research Institute, March 1994, (in Japanese)

4) Susumu Ohno, Katsuya Takahashi : "Evaluation of strong-motion attenuation relation using near-source data in California", Proceedings of the 9th Japan Earthquake Engineering Symposium, 1994, (in Japanese)

5) "Preliminary report on the principal geotechnical aspects of the January 17", 1994 Northridge Earthquake, EERC Report No. UCB/EERC-94/08

6) Katayama, $\mathrm{T}$ : "Seismic risk analysis in terms of acceleration response spectra", Proceedings of 2 nd UsNational Conference on Earthquake Engineering, 1979

7) "Waveform and its analysis of the 1995 Hyogo-Ken-
Nanbu Earthquake (II)", JR Earthquake Information No. 23d, March, 1996, (in Japanese)

8) "Maps of Active Faults in Japan with an explanatory text", The research group for active faults of Japan, University of Tokyo Press, 1991

9) Sato, R. : "Handbook of parameters of seismic faults in Japan", 1989, Kajima Press

10) Wang, H, Murono, Y, Nisimura, A : "On evaluation of ground motion near seismic faults based on strong seismic records", Proceedings of the 2nd Urban Earthquake Disaster Symposium, Japan, 1997, (in Japanese)

11) Kameda, H, Okumura, T. : "Seismic hazard estimation based on active fault data and historical earthquake data", Proceedings of the Japan society of civil engineers, No.362/I-4, Oct. 1985 (in Japanese)

12) Naganawa, T, Wang, H, et al. : "Seismic risk analysis based on the data of active fault and historical earthquakes", Proceedings of the 10th Japan Earthquake Engineering Symposium, 1998 (in Japanese)

13) Toki, K, Sato, T, etc. : "Seismic risk analyses in Kinki district based on historical earthquake data and active fault data", Bulletin of Disaster Prevention Research Institute, Kyoto University, Vol.34, Part B-2, 1991 (in Japanese)

14) Gotou, Y., Ejiri, J. : "The characteristics of amplification at the Tarzana observation station in Northridge earthquake", Proceedings of Amplification of Ground Motion on Soft Ground Symposium, Japan, 1994

15) Utsu, T. : "Catalog of Large Earthquakes in the Region of Japan from 1885 through 1980", Bulletin of the Earthquake Research Institute University of Tokyo, Vol.57, 1982 (in Japanese) 